\title{
ARTICLE
}

\section{A multi-targeting drug design strategy for identifying potent anti-SARS-CoV-2 inhibitors}

Peng-xuan Ren ${ }^{1}$, Wei-juan Shang ${ }^{2}$, Wan-chao Yin ${ }^{3}$, Huan Ge ${ }^{4}$, Lin Wang ${ }^{1}$, Xiang-lei Zhang ${ }^{1}$, Bing-qian $\mathrm{Li}^{1,5}$, Hong-lin Li ${ }^{4}$, Ye-chun Xu ${ }^{3,6}$, Eric H. Xu ${ }^{3,6}$, Hua-liang Jiang ${ }^{1,3,6}$, Li-li Zhu ${ }^{4}$, Lei-ke Zhang ${ }^{2}$ and Fang Bai ${ }^{1}$

The COVID-19, caused by SARS-CoV-2, is threatening public health, and there is no effective treatment. In this study, we have implemented a multi-targeted anti-viral drug design strategy to discover highly potent SARS-CoV-2 inhibitors, which simultaneously act on the host ribosome, viral RNA as well as RNA-dependent RNA polymerases, and nucleocapsid protein of the virus, to impair viral translation, frameshifting, replication, and assembly. Driven by this strategy, three alkaloids, including lycorine, emetine, and cephaeline, were discovered to inhibit SARS-CoV-2 with $\mathrm{EC}_{50}$ values of low nanomolar levels potently. The findings in this work demonstrate the feasibility of this multi-targeting drug design strategy and provide a rationale for designing more potent anti-virus drugs.

Keywords: SARS-CoV-2 inhibitors; RdRp; host ribosome; Virus RNA

Acta Pharmacologica Sinica (2022) 43:483-493; https://doi.org/10.1038/s41401-021-00668-7

\section{INTRODUCTION}

The COVID-19 (Coronavirus disease-2019), caused by a novel coronavirus (SARS-CoV-2), has spread worldwide and remains out of control [1-4]. SARS-CoV-2 is an enveloped, positive-sensed, and single-stranded RNA beta coronavirus (CoV) [5, 6]. At present, there are seven human CoV strains identified, which includes: (1) four low-pathogenicity members: 229E (alpha coronavirus), NL63 (alpha coronavirus), OC43 (beta coronavirus), and HKU1 (beta coronavirus); and (2) three highly pathogenic members: MERS-CoV (the beta coronavirus that causes Middle East Respiratory Syndrome, abbreviated as MERS), SARS-CoV (the beta coronavirus that causes a severe acute respiratory syndrome, named as SARS) as well as SARS-CoV-2 [7]. SARS-CoV-2 encodes four structural proteins, including spike, envelope, membrane, and nucleocapsid protein ( $\mathrm{N}$ protein), as well as 15 nonstructural proteins (abbreviated as Nsps) [1, 8]. While living cells are infected, the virus can directly access the ribosomes of the host cell to produce proteins for new viruses. Nsps are assembled into a multi-subunit polymerase complex to create an environment suitable for transcription and replication of the viral genome. The viral genomes then form mature virions with viral structural proteins [9]. It is worth noting that during the coronavirus replication cycle, these targets, including RNA-dependent RNA polymerase (RdRp), $\mathrm{N}$ protein, ribosome, and -1 programmed ribosomal frameshifting ( -1 PRF) region, are involved in interacting with RNA, which herein providing a common feature for developing multi-targeting drugs that could have maximal anti-viral efficacy.
Although ribosome is one necessary organelle in living cells for producing proteins for host cells, it can be regarded as one potential drug target because of its essential role in viral protein translation [10]. The human ribosome is known as the $80 \mathrm{~S}$ ribosome, composed of a small $40 \mathrm{~S}$ subunit and a large $60 \mathrm{~S}$ subunit. There are four main functional sites embedded in the whole ribosome: (1) the mRNA binding site; (2) the tRNA-binding sites which contain the $A$ (aminoacyl)-site, $P$ (peptidyl)-site, and $E$ (exit)-site; (3) the peptidyl transfer center (PTC); and (4) the binding site for translational factors [11]. Previous studies showed that these functional sites were identified as druggable binding sites within ribosomes [12]. Besides, virus-infected cells produce more proteins than normal cells, which means that ribosome seems to be very important for replicating the virus. In total, ribosomes could be counted as a potential target for treating viral infection [13].

SARS-CoV-2 recruits -1 PRF, which involves a shift in the reading frame of the ribosome at a specific location in the RNA message, that is, 5-7 nucleotides downstream of the 'slippery' sequence where the reading-frame shift occurs, typically exists a pseudoknot, to control the expression of viral proteins, including RdRp [14]. Some works of literature showed that mutations or molecular binders of -1 PRF could significantly attenuate viral propagation $[15,16]$, demonstrating that the RNA genome of the virus could be a considerable druggable target.

$\mathrm{RdRp}$, as a crucial drug target for anti-coronaviruses, plays an essential role in the process of replication and transcription of RNA viruses $[17,18]$. The RdRp of SARS-CoV-2 is composed of nsp12,

\footnotetext{
${ }^{1}$ School of Life Science and Technology, and Shanghai Institute for Advanced Immunochemical Studies, ShanghaiTech University, Shanghai 201210 , China; ${ }^{2}$ State Key Laboratory of Virology, Wuhan Institute of Virology, Center for Biosafety Mega-Science, Chinese Academy of Sciences, Wuhan 430071, China; ${ }^{3}$ CAS Key Laboratory of Receptor Research, Shanghai Institute of Materia Medica, Chinese Academy of Sciences, Shanghai 201203, China; ${ }^{4}$ State Key Laboratory of Bioreactor Engineering, Shanghai Key Laboratory of New

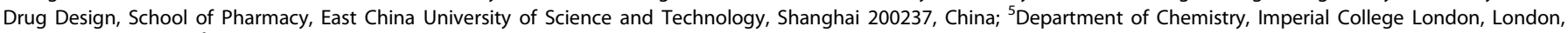
United Kingdom and ${ }^{6}$ University of Chinese Academy of Sciences, Beijing 100049, China

Correspondence: Li-li Zhu (zhulfl@ecust.edu.cn) or Lei-ke Zhang (zhangleike@wh.iov.cn) or Fang Bai (baifang@shanghaitech.edu.cn)

These authors contributed equally: Peng-xuan Ren, Wei-juan Shang, Wan-chao Yin, Huan Ge, Lin Wang
}

Received: 12 January 2021 Accepted: 22 March 2021

Published online: 27 April 2021 

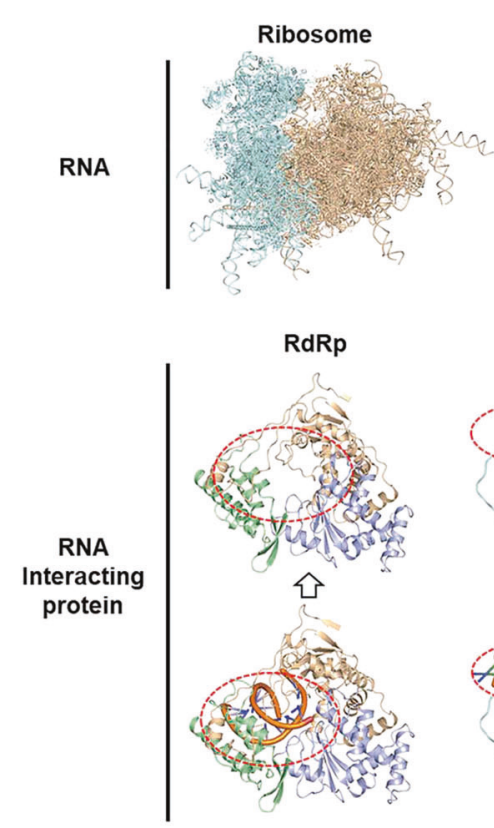

RdRp-RNA

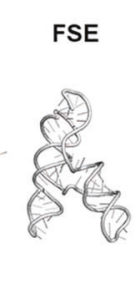

$\mathrm{N}$ protein

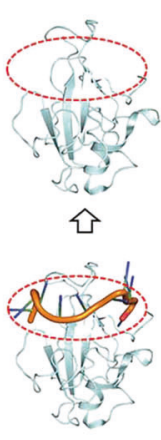

N protein-RNA

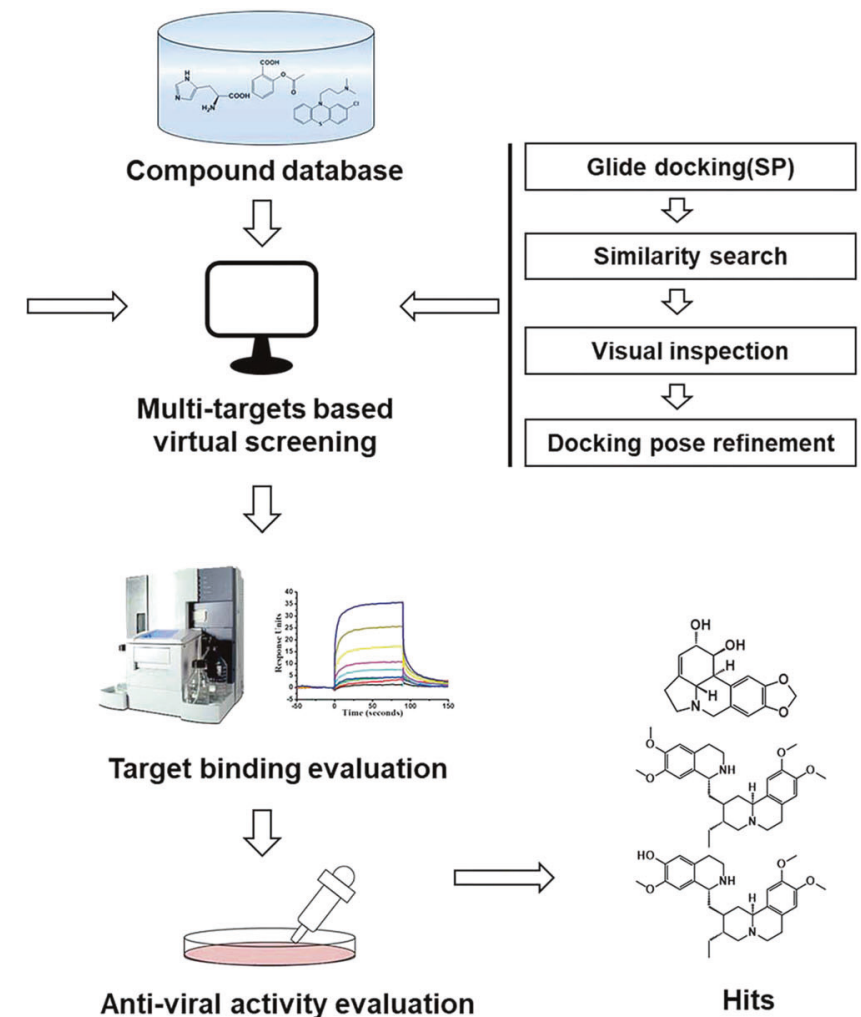

Fig. 1 Schematic illustration of the multi-targeting-based anti-SARS-CoV-2 inhibitor identification workflow designed by combining computational methods with experimental techniques. The cartoon models represent the structures of four potential targets. The compound database is shown as a cylinder. The experimental techniques are shown as the pictures of instruments and equipments.

which is a catalytic subunit, and two accessory subunits, nsp7 and nsp8, which can stimulate nsp12 polymerase activity. The nsp12 subunit includes a nidovirus RdRp-associated nucleotidyltransferase (NiRAN) domain in the $\mathrm{N}$-terminal portion, and an interface domain, which is responsible for connecting the Cterminal RdRp catalytic domain and NiRAN domain [19-21]. The core structure of RdRp presents a large and deep groove domain, resembling a human right hand, interconnected by 'fingers', 'palm', and 'thumb' subdomains, which form the catalytic site of RNA synthesis. The catalytic site, comprising of the residues of SER 759, ASP 760, and ASP 761 (SDD), which lies in the motif C, is involved in primer binding for RdRp activity [20].

Being one of the multifunctional structural proteins in SARSCoV-2, $\mathrm{N}$ protein plays a vital role in constructing helical ribonucleoproteins by interacting with the viral RNA genome and regulating viral RNA synthesis during the processes of replication and transcription [22]. N protein contains three highly conserved domains: (1) an N-terminal RNA-binding domain (NTD), which is primarily responsible for RNA-binding; (2) a C-terminal dimerization domain (CTD), which mediates $\mathrm{N}-\mathrm{N}$ homotypic interactions; and (3) a poorly structured central Ser/Arg(SR)-rich linker which connects NTD and CTD and contains multiple putative sites of phosphorylation [23, 24]. Previous studies showed that $\mathrm{N}$ protein could be used as another potential target for developing small-molecular anti-virus drugs via destroying the assembling process of virions [25].

In this work, three alkaloid compounds, lycorine, emetine, and cephaeline, were identified to be potent inhibitors of SARS-CoV-2 by simultaneously working on these four potential targets. To achieve this, a comprehensive workflow, which was composed of computational methods and experimental techniques, was designed as shown in Fig. 1, presenting a new multi-targeting anti-virus inhibitor designing strategy.

\section{MATERIALS AND METHODS}

Identification of candidate multi-targeting drugs

The surfaces of electrostatic potentials of the RNA binding sites of $\mathrm{N}$ protein and RdRp illustrate the similar charged and polarizable binding sites for designing drugs (Supplementary Fig. S1). To discover potential candidate drugs that can bind both with RdRp and $\mathrm{N}$ protein, virtual screening was carried out with compound data sets obtained from DrugBank 5.0 (www.drugbank.ca) and anti-infection database (MedChemExpress). The compounds were firstly pre-processed by using the LigPrep module in Maestro (Schrödinger 2020-1) to predict protonation states and generate their 3D low-energetical conformations. All compounds in the database were converted to their most probable ionized state at $\mathrm{pH} 7.0 \pm 2.0$. Default settings were used for all remaining parameters.

At the very beginning of this work, the molecular structure of the $\mathrm{N}$ protein of SARS-CoV-2 had not been released. Hence, a computational modeled structure was generated and released from I-TASSER (https://zhanglab.ccmb.med.umich.edu/COVID-19/) [26]. And another predicted structure was generated by trRossetta [27]. There is no apparent difference between the predicted structures (Supplementary Fig. S2a). The structure predicted by ITASSER was used to perform the virtual screening. The sequences of $\mathrm{N}$ proteins of the $\beta$ coronavirus were retrieved from the UniProt (https://www.uniprot.org/) [28]. The homologous sequence alignment of $\mathrm{N}$ proteins of the $\beta$ coronavirus was performed using MAFFT, [29] and the final map was obtained from Espript 3.0 [30] (Supplementary Fig. S3). In consideration of the high sequence identity of $\mathrm{N}$ proteins between SARS-CoV-2 and HCoV-OC43, the experimentally obtained complex structure of HCoV-OC43 NTD (Nterminal domain) with an inhibitor, noted as PJ34 ( $N$-(6-oxo-5,6dihydrophenanthridin-2-yl)(N,N-dimethylamino)acetamide hydrochloride) (PDB code: 4KXJ), was used as a reference for 
determining the druggable active site (Supplementary Fig. S4). Not long after this, the structure of the SARS-CoV-2 RNA binding domain was retrieved from the protein structure databank (PDB code: 6VYO), and there is no obvious difference between the predicted and experimental structures (Supplementary Fig. S2a). Therefore, the selected candidate drugs for this work were still redocked to the experimental structure to re-analyze the proteinligand interactions. The above-related protein structures were structurally refined by the Protein Preparation Wizard in Maestro (Schrödinger 2020-1) for assigning correct protonation states as well as formal charges, adding missing residues, and optimizing three-dimensional conformations. The grid was centered on the centroid of residues $\mathrm{Y} 109$ and $\mathrm{Y} 111$. We defined the binding region by a $20 \AA \times 20 \AA \times 20 \AA$ box for grid generation. Default settings were used for all remaining parameters.

As with the case of nucleocapsid phosphoprotein, we used the computationally modeled structures of $\mathrm{RdRp}$ generated by ITASSER and trRossetta to discover RdRp binders (Supplementary Fig. S2b), and re-analysis of protein-ligand interaction was performed against the experimentally released structure of RdRp (PDB code: 7BV1). The protein structure was firstly prepared and refined by using the same method described for treating nucleocapsid phosphoprotein. Referencing the remdesivirbinding site (Supplementary Fig. S5), the grid was centered on the centroid of residues R555, S759, D760, and D761. We defined the binding region by a $20 \AA \times 20 \AA \times 20 \AA$ box for grid generation. Default settings were used for all remaining parameters. The docking simulations were performed against the RNA binding domain of RdRp.

To analyze the interaction between ligands and the complex structure of RdRp with RNA, the ligands were docked to the experimentally released complex structure of RdRp with RNA (PDB code: 7BZF). The structure was processed by using the same workflow for treating the apo structure of RdRp described above.

Docking simulations were performed by using Glide(v8.7) [31] in Maestro, with SP (standard precision). Five poses were written out for each ligand, and the rest conditions were set as default. Enlightened by the common pharmacophores of the amine group and aromatic group contained on anti-virus inhibitors, i.e., chloroquine and cinanserin, $20 \%$ of top-ranked candidate ligands were further filtered by using the 3D molecular similarity calculation method SHAFTs by taking these two inhibitors as query molecules, respectively. Chloroquine and cinanserin were two reported anti-virus inhibitors $[32,33]$. The potential anti-SARSCoV-2 mechanisms of chloroquine include disrupting the endocytic pathway, blocked sialic acid receptors, restricting $\mathrm{pH}$ mediated spike(S) protein cleavage at the angiotensinconverting enzyme 2 (ACE2) binding site, and preventing cytokine storm $[34,35]$. Cinanserin was also reported to inhibit SARS-CoV-2 Mpro [33]. All these concerned targets of chloroquine and cinanserin were essential targets for controlling COVID-19, and we believed their common pharmacophores, i.e., the amine group and aromatic group, could contribute to the most anti-virus effect. Hence, we performed such a filtration on those candidate drugs to find out the most possible one which not only binds strongly to $\mathrm{RdRp}$ and $\mathrm{N}$ protein but also contains amine and aromatic groups. Then, visual inspection was performed to analyze the predicted binding modes between the top-ranked ligands and the proteins. As a result, lycorine, emetine, and cephaeline were selected. Subsequently, the docked poses were refined by Prime MM-GBSA in maestro (Supplementary Table S1).

Excitingly, through reviewing the reported target information of lycorine, emetine, and cephaeline, we found these compounds can also bind with the ribosome. The complex structures of the yeast $80 \mathrm{~S}$ ribosome with lycorine and the small subunit of Plasmodium falciparum ribosome with emetine have been experimentally obtained and deposited in the protein structure databank (PDB codes: $4 \mathrm{U} 4 \mathrm{U}$ and 3J7A). The structure of the human 805 ribosome was retrieved from the protein structure databank (PDB code: 4V6X). Three-dimensional models of the homo ribosome in complex with lycorine and emetine were computationally constructed by referring to the experimental complex structures of the lycorine contained yeast ribosomes and emetine contained $P f$ ribosomes. The cephaeline was superimposed with emetine in the constructed model based on the concept that compounds sharing structural and pharmacophore similarities may have a relatively similar binding model. Subsequently, molecular structure refinement was performed to optimize the modeled complex structures by Prime MM-GBSA (Supplementary Table S1).

The structure of the frameshift stimulation element (FSE) of -1 PRF was retrieved from the protein structure databank (PDB code: 7ACT). The structure of FSE was refined by the Protein Preparation Wizard in Maestro (Schrödinger 2020-1) for assigning correct protonation states as well as formal charges and optimizing threedimensional conformations. The grid was centered on the centroid of ribonucleotides $\mathrm{G} 19, \mathrm{C} 43, \mathrm{G} 46$, and $\mathrm{A} 76$. We defined the ligand diameter midpoint box by a $40 \AA \times 40 \AA \times 40 \AA$ box and the binding region by a $36 \AA \times 36 \AA \times 36 \AA$ enclosing box for grid generation. Default settings were used for all remaining parameters. Docking simulations were performed using Glide(v8.7) in Maestro, with SP (standard precision). Ten poses were written out for each ligand, and the rest conditions were set as default. Then, visual inspection was performed to select the predicted binding modes between ligands and FSE. Subsequently, structural refinement was performed to optimize the modeled complex structures by employing Prime MM-GBSA (Supplementary Table S1).

\section{Constructs and expression of the RdRp complex}

The RdRp complex was prepared according to the same method $[20,29]$ reported as described below. The full-length gene of the SARS-CoV-2 nsp12 (residues 1-932) was chemically synthesized with codon optimization (General Biosystems). The gene was cloned into a modified pFastBac baculovirus expression vector containing a $5^{\prime}$ ATG starting sequence and C-terminal Tobacco Etch Virus (TEV) protease site followed by a His8 tag. The plasmid contains an additional methionine at the $\mathrm{N}$-terminus and GGSENLYFQGHHHHHHHH at the C-terminus of nsp12. The fulllength genes for nsp7 (residues 1-83) and, nsp8 (residues 1-198) were cloned into the pFastBac vector containing a 5' ATG starting sequence. All constructs were generated using the Phanta Max Super-Fidelity DNA Polymerase (Vazyme Biotech Co., Ltd) and verified by DNA sequencing. All constructs were expressed in Spodoptera frugiperda (Sf9) cells. Cell cultures were grown in ESF 921 serum-free medium (Expression Systems) to a density of 2-3 million cells per $\mathrm{mL}$ and then infected with three separate baculoviruses at a ratio of 1:2:2 for nsp12, nsp7 and nsp8 at a multiplicity of infection (m.o.i.) of about 5. For the nsp12 subunit, the cell cultures were grown in ESF 921 serumfree medium (Expression Systems) to a density of 2-3 million cells per $\mathrm{mL}$ and then infected with the only baculoviruse for nsp 12 at a multiplicity of infection (m.o.i.) of about 5. The cells were collected $48 \mathrm{~h}$ after infection at $27^{\circ} \mathrm{C}$, and cell pellets were stored at $-80^{\circ} \mathrm{C}$ until use.

Besides, the genes of nsp7 and nsp8 were cloned into a modified pET-32a $(+)$ vector containing a $5^{\prime}$ ATG starting sequence and C-terminal His8 tag with a TEV cleavage site for expression in $E$. coli. Plasmids were transformed into BL21(DE3) (Invitrogen). Bacterial cultures were grown to an $O D_{600}$ of 0.6 at 37 ${ }^{\circ} \mathrm{C}$, and then the expression was induced with a final concentration of $0.1 \mathrm{mM}$ of isopropyl $\beta$-D-1-thiogalactopyranoside (IPTG) and the growth temperature was reduced to $16^{\circ} \mathrm{C}$ for $18-20 \mathrm{~h}$. The bacterial cultures were pelleted and stored at $-80^{\circ} \mathrm{C}$ until use. 
486

Purification of the RdRp complex

The purification of nsp7 and nsp8 expressed in bacteria was similar to the purification of nsp7 and nsp8 reported previously [36]. Briefly, bacterial cells were lysed with a high-pressure homogenizer operating at 800 bar. Lysates were cleared by centrifugation at $25,000 \times g$ for $30 \mathrm{~min}$ and were then bound to Ni-NTA beads (GE Healthcare). After a wash with buffer containing $50 \mathrm{mM}$ imidazole, the protein was eluted with buffer containing $300 \mathrm{mM}$ imidazole. The tag was removed with incubation of TEV protease overnight, and protein samples were concentrated with $3 \mathrm{kDa}$ or $30 \mathrm{kDa}$ molecular weight cut-off centrifuge filter units (Millipore Corporation) and then size-separated by a Superdex 75 Increase 10/300 GL column in $25 \mathrm{mM}$ HEPES pH 7.4, $200 \mathrm{mM}$ sodium chloride, $5 \%(\mathrm{v} / \mathrm{v})$ glycerol. The fractions for the $\mathrm{nsp} 7$ or nsp8 were collected, concentrated to about $10 \mathrm{mg} / \mathrm{mL}$, and stored at $-80^{\circ} \mathrm{C}$ until use.

The insect cells containing the co-expressed RdRp complex were resuspended in binding buffer of $25 \mathrm{mM}$ HEPES pH 7.4, 300 $\mathrm{mM}$ sodium chloride, $25 \mathrm{mM}$ imidazole, $1 \mathrm{mM}$ magnesium chloride, $0.1 \%$ (v/v) IGEPALCA-630 (Anatrace), $1 \mathrm{mM}$ tris (2carboxyethyl) phosphine (TCEP), $10 \%$ (v/v) glycerol with additional EDTA-free Protease Inhibitor Cocktail (Bimake), and then incubated with agitation for $20 \mathrm{~min}$ at $4{ }^{\circ} \mathrm{C}$. The incubated cells were lysed with a high-pressure homogenizer operating at 500 bar. The supernatant was isolated by centrifugation at $30,000 \times g$ for 30 min, followed by incubation with Ni-NTA beads (GE Healthcare) for $2 \mathrm{~h}$ at $4{ }^{\circ} \mathrm{C}$. After binding, the beads were washed with 20 column volumes of wash buffer of $25 \mathrm{mM}$ HEPES, pH 7.4, $300 \mathrm{mM}$ sodium chloride, $25 \mathrm{mM}$ imidazole, $1 \mathrm{mM}$ magnesium chloride, $1 \mathrm{mM}$ TCEP, and $10 \%(\mathrm{v} / \mathrm{v})$ glycerol. The protein was eluted with 3-4 column volumes of elution buffer of $25 \mathrm{mM}$ HEPES pH 7.4, $300 \mathrm{mM}$ sodium chloride, $300 \mathrm{mM}$ imidazole, $1 \mathrm{mM}$ magnesium chloride, 1 $\mathrm{mM}$ TCEP, and $10 \%(\mathrm{v} / \mathrm{v})$ glycerol.

The co-expressed RdRp complex was incubated with additional nsp7 and nsp8 from the bacterial expression in a 1:1:2 molar ratios and incubated at $4{ }^{\circ} \mathrm{C}$ for $4 \mathrm{~h}$. Incubated RdRp complex was concentrated with a $100 \mathrm{kDa}$ molecular weight cut-off centrifugal filter unit (Millipore Corporation) and then size-separated by a Superdex 200 Increase 10/300 GL column in 25 mM HEPES pH 7.4, $300 \mathrm{mM}$ sodium chloride, $1 \mathrm{mM}$ magnesium chloride, $1 \mathrm{mM}$ TCEP. The fractions for the monomeric complex were collected for the next step of experiments.

\section{Purification of the SARS-CoV-2 nsp12}

The purification of SARS-CoV-2 nsp12 from SF9 cells was similar to the above purification of RdRp complex. The insect cells containing nsp12 were resuspended in binding buffer of $25 \mathrm{mM}$ HEPES $\mathrm{pH} 7.4,300 \mathrm{mM}$ sodium chloride, $25 \mathrm{mM}$ imidazole, $1 \mathrm{mM}$ magnesium chloride, $0.1 \%(\mathrm{v} / \mathrm{v})$ IGEPALCA-630 (Anatrace), $1 \mathrm{mM}$ tris (2-carboxyethyl) phosphine (TCEP), 10\% (v/v) glycerol with additional EDTA-free Protease Inhibitor Cocktail (Bimake), and then incubated with agitation for $20 \mathrm{~min}$ at $4^{\circ} \mathrm{C}$. The incubated cells were lysed with a high-pressure homogenizer operating at 500 bar. The supernatant was isolated by centrifugation at $30,000 \times g$ for $30 \mathrm{~min}$, followed by incubation with Ni-NTA beads (GE Healthcare) for $2 \mathrm{~h}$ at $4{ }^{\circ} \mathrm{C}$. After binding, the beads were washed with 20 column volumes of wash buffer of $25 \mathrm{mM}$ HEPES, $\mathrm{pH} 7.4,300 \mathrm{mM}$ sodium chloride, $25 \mathrm{mM}$ imidazole, $1 \mathrm{mM}$ magnesium chloride, $1 \mathrm{mM}$ TCEP, and $10 \%(\mathrm{v} / \mathrm{v})$ glycerol. The protein was eluted with 3-4 column volumes of elution buffer of $25 \mathrm{mM}$ HEPES pH 7.4, $300 \mathrm{mM}$ sodium chloride, $300 \mathrm{mM}$ imidazole, $1 \mathrm{mM}$ magnesium chloride, $1 \mathrm{mM}$ TCEP, and $10 \%(\mathrm{v} / \mathrm{v})$ glycerol. The eluted protein was concentrated with a $100 \mathrm{kDa}$ molecular weight cut-off centrifugal filter unit (Millipore Corporation) and then size-separated by a Superdex 200 Increase $10 / 300$ GL column in $25 \mathrm{mM}$ HEPES $\mathrm{pH} 7.4,300 \mathrm{mM}$ sodium chloride, $1 \mathrm{mM}$ magnesium chloride, $1 \mathrm{mM}$ TCEP. The fractions for the monomeric complex were collected for the next step of experiments.
Preparation of the RNA bound RdRp complex

A short RNA oligonucleotide with the sequence of 5'-GCUAUGU GAGAUUAAGAAUU- $3^{\prime}$ was used as the primer strand, and a longer RNA oligonucleotide with the sequence of $5^{\prime}$-UUUUUUUUU UAAUUCUUAAUCUCACAUAGC- $3^{\prime}$ was used as a template strand. To anneal the RNA duplex, both oligonucleotides were mixed at an equal molar ratio in annealing buffer $(10 \mathrm{mM}$ Tris- $\mathrm{HCl}, \mathrm{pH}$ 8.0, $25 \mathrm{mM} \mathrm{NaCl}$, and $2.5 \mathrm{mM}$ EDTA), denatured by heating to $94^{\circ} \mathrm{C}$ for $5 \mathrm{~min}$ and then slowly cooled to room temperature.

For the RNA bound RdRp complex, the concentrated RdRp complex were diluted to $0.5 \mathrm{mg} / \mathrm{mL}$ with a buffer of $25 \mathrm{mM}$ HEPES $\mathrm{pH} 7.4,100 \mathrm{mM}$ sodium chloride, $2 \mathrm{mM}$ magnesium chloride, 1 mM TCEP, combined with the annealed template-primer RNA in a 1:1.5 molar ratio and incubated at $4{ }^{\circ} \mathrm{C}$ for $0.5 \mathrm{~h}$.

Surface plasmon resonance (SPR) based binding affinity assays We carried out surface plasmon resonance (SPR) experiments using a BIAcore T200 to evaluate the binding affinities between the compounds and proteins. The proteins SARS-CoV-2 $\mathrm{N}$ protein and nsp 12 were immobilized covalently on a CM5 chip with the final immobilization levels equal to 9636 and 19370 resonance units (RU), respectively. The SARS-CoV-2 nsp12-nsp7-nsp8-RNA complex was immobilized on a Ni-NTA chip, and the final immobilization level was $6600 \mathrm{RU}$. The running buffer used in the experiments was PBS, $0.005 \%$ (vol/vol) surfactant P20, pH 7.4, and $1 \%$ DMSO. Lycorine (S3903) was purchased from Selleck (https://www.selleck.cn/). Emetine (HY-B1479A) was purchased from MedChemExpress (https://www.medchemexpress.cn/). Cephaeline (BP0330) was purchased from Biopurify (http://www. biopurify.cn/). All compounds were diluted using the running buffer from the top concentration. The measurements were performed at a flow rate of $30 \mu \mathrm{L} / \mathrm{min}$. For each binding cycle, the analyte was injected for $90 \mathrm{~s}$ and the dissociation time was $180 \mathrm{~s}$. Data were analyzed using BIAevaluation 1.1 software. Kinetic data were analyzed for the compounds binding to SARS-CoV-2 N protein and nsp12. For the binding data between the compounds and the SARS-CoV-2 nsp12-nsp7-nsp8-RNA complex, the affinity values were calculated using the steady-state fitting model. Each measurement was repeated twice times.

\section{Cell lines and viruses}

African green monkey kidney Vero E6 cells (ATCC-1586) were maintained in Dulbecco's modified Eagle's medium (DMEM) with $10 \%$ fetal bovine serum (FBS) and $1 \%$ penicillin-streptomycin antibiotics. Cells were kept at $37^{\circ} \mathrm{C}$ in a $5 \% \mathrm{CO}_{2}$ atmosphere. The strain (nCoV-2019BetaCoV/Wuhan/WIV04/2019) of SARS-CoV-2 was obtained from National Virus Resource Center, isolated from a clinical patient [5]. The virus strain was propagated in Vero E6 cells.

Antiviral activities and cytotoxicity measurement for lycorine, emetine, and cephaeline

In our study, Vero E6 cells were pre-seeded to 48-well plates $(50,000$ cells/well) for $16-18 \mathrm{~h}$, treated with medium containing gradient concentration of the three compounds at $100 \mu \mathrm{L} /$ well for $1 \mathrm{~h}$. Then, the cells were inoculated with SARS-CoV-2 at the multiplicity of infection (MOI) of 0.05 for $1 \mathrm{~h}$. After the supernatant was removed, the cells washed twice with PBS, and fresh medium was re-added containing gradient concentrations of the three compounds at $200 \mu \mathrm{L} /$ well. The cells were incubated at $37^{\circ} \mathrm{C}$ for $24 \mathrm{~h}$. The cell supernatant was collected; antiviral activities were evaluated by quantifying viral copy numbers in the cell supernatant via real-time fluorescence quantitative PCR (qRT-PCR). DMSO was used in control. The inhibition rates of the three compounds were calculated based on the viral copy numbers, and the $50 \%$ maximal effective concentration $\left(E_{50}\right)$ was calculated with Graphpad Prism software 8.0. The experiments were done in 


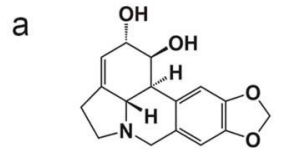

Lycorine

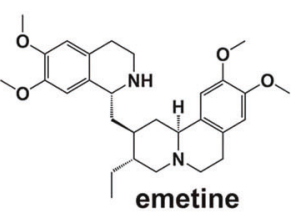

emetine

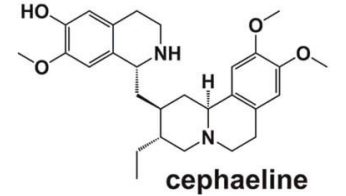

b
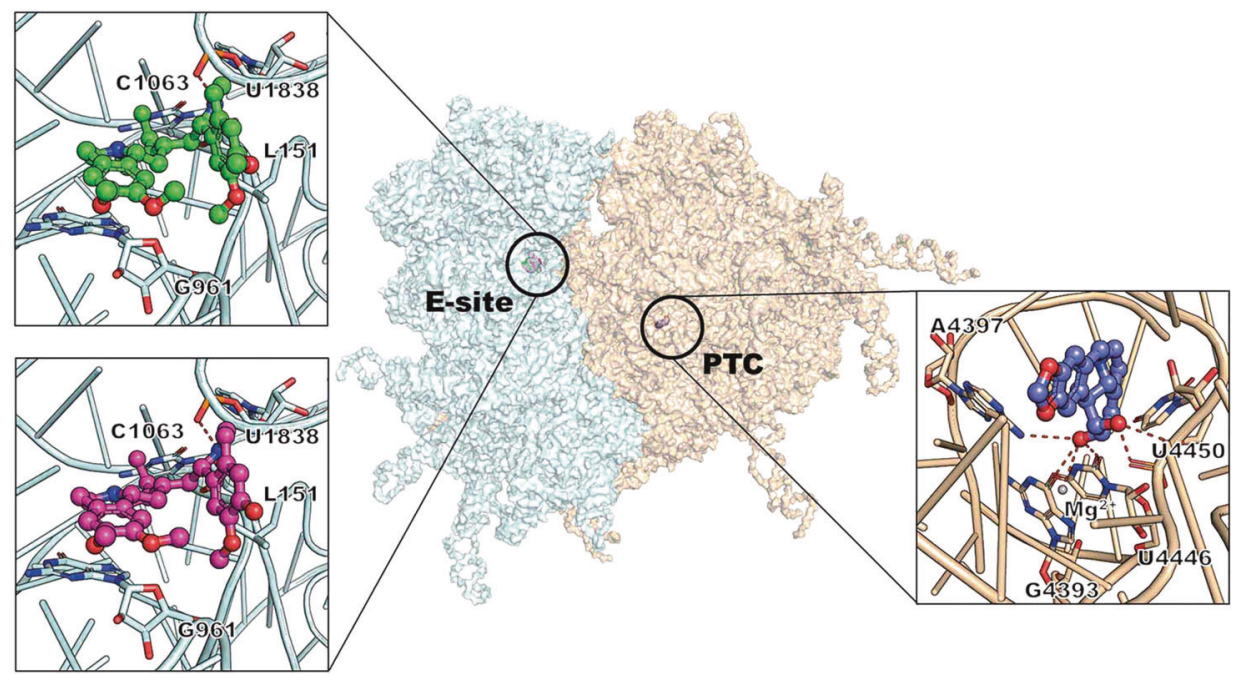

Fig. 2 Computationally predicted molecular mechanism underlying the inhibition of viral translation of lycorine, emetine and cephaeline by targeting ribosome. a Chemical structure of lycorine, emetine and cephaeline. $\mathbf{b}$ Predicted binding model of lycorine, emetine and cephaeline with human $80 \mathrm{~S}$ ribosome. The $40 \mathrm{~S}$ small subunit(palecyan) and the $60 \mathrm{~S}$ large subunit(wheat) are shown in surface. Lycorine (blue), emetine(green) and cephaeline(magentas) bound at the active sites (E-site and PTC) are represented as stick-ball models. Three zoomup models illustrate detailed molecular interactions between the ligands and the target. Red dash lines are hydrogen bonds or salt bridges formed between the ligand and targets.

triplicates, and all the infection experiments were performed at biosafety level 3 (BSL-3).

For cytotoxicity measurement in Vero E6 cells, the cells were added to a 96 -well plate (20,000 cells/well), the next day, added with medium containing gradient concentrations of the three compounds at $100 \mu \mathrm{L} /$ well. The $\mathrm{CC}_{50}$ of the three compounds was determined after $24 \mathrm{~h}$ using the CCK8 assay kit, and the $\mathrm{CC}_{50}$ of the three compounds was calculated with Graphpad Prism software 8.0.

For cytotoxicity measurement in Huh-7 cells and HEK293T cells, Huh-7 cells and HEK293T cells were seeded into a 96-well plate at a cell density of 15000 per well. After adherence for $24 \mathrm{~h}$, medium containing gradient concentration of compound $200 \mu \mathrm{L}$ per well was added, DMSO was used in control and the group without any cell was used as blank control. Next day, after the culture medium was removed, CCK8 was added to the plate for $2 \mathrm{~h}$ at $37^{\circ} \mathrm{C}$. The absorbance was measured at $450 \mathrm{~nm}$ using a microplate reader (Synergy $\mathrm{H} 1 /$ Synergy2, Biotek). The $\mathrm{CC}_{50}$ of the three compounds was calculated with Graphpad Prism software 8.0. All experiments were performed in triplicate.

\section{Statistical analysis}

The affinity values were calculated by BIAevaluation 1.1 software. The binding affinity curves were fitted by origin software 7.0. The $\mathrm{EC}_{50}$ and $\mathrm{CC}_{50}$ values were calculated with Graphpad Prism software 8.0. All data were expressed as the means \pm SD of three independent experiments.

\section{RESULTS}

Lycorine, emetine, and cephaeline may inhibit viral protein synthesis by interacting with the host ribosome

As mentioned in the Methods session, the anti-virus activity of lycorine and emetine may be contributed by their interaction with the human ribosome (homo ribosome) on different catalytic active sites. By comparing the compound structures of these two molecules with cephaeline, it can be noticed that all three compounds are alkaloid analogs and structurally similar (Fig. 2a). Especially, cephaeline is a desmethyl analog of emetine [37], which may be better tolerated in patients than emetine, exhibiting a similar efficacy against both ZIKV and EBOV infections by interacting with the same set of drug targets, including ribosome [38]. Lycorine and emetine were previously reported to inhibit viral translation $[38,39]$. It has also been reported that emetine and lycorine can inhibit translation respectively by targeting tRNA E-site (exit-site) of yeast ribosomal small subunit and the peptidyl transfer site of Plasmodium falciparum ribosomal ( $P f$ ribosomes) large subunit $[12,40]$. The functional regions of ribosomes are conserved in eukaryotes such as yeast, Plasmodium falciparum, and homo sapiens $[12,40,41]$, which allows us to assume that emetine, cephaeline, and lycorine can also bind with the homo ribosome similarly. Thus, three-dimensional models of the human ribosome in complex with lycorine and emetine were computationally constructed respectively by referring to the experimental complex structures of the lycorine contained yeast ribosomes and emetine contained $P f$ ribosomes. The binding modes of the three compounds with the ribosome were illustrated in Fig. 2b. A salt bridge was formed between the quinolizine ring of emetine (cephaeline) and U1838, which was observed from the predicted binding mode. Besides, according to the modeling results, it can be found that the benzo[a]quinolizine ring may mimic a basestacking interaction with G961 to strengthen the bindings. Unlike emetine and cephaeline, lycorine was found to fit snugly into the peptidyl transfer site, being stabilized by the hydrogen bonds formed with A4397, U4450, U4446, and G4393. Beyond that, a coordinated bond between the hydroxyl group at C-2 position and $\mathrm{Mg}^{2+}$ was observed. These complicated interactions again confirm the bindings between ligands and the ribosome. 


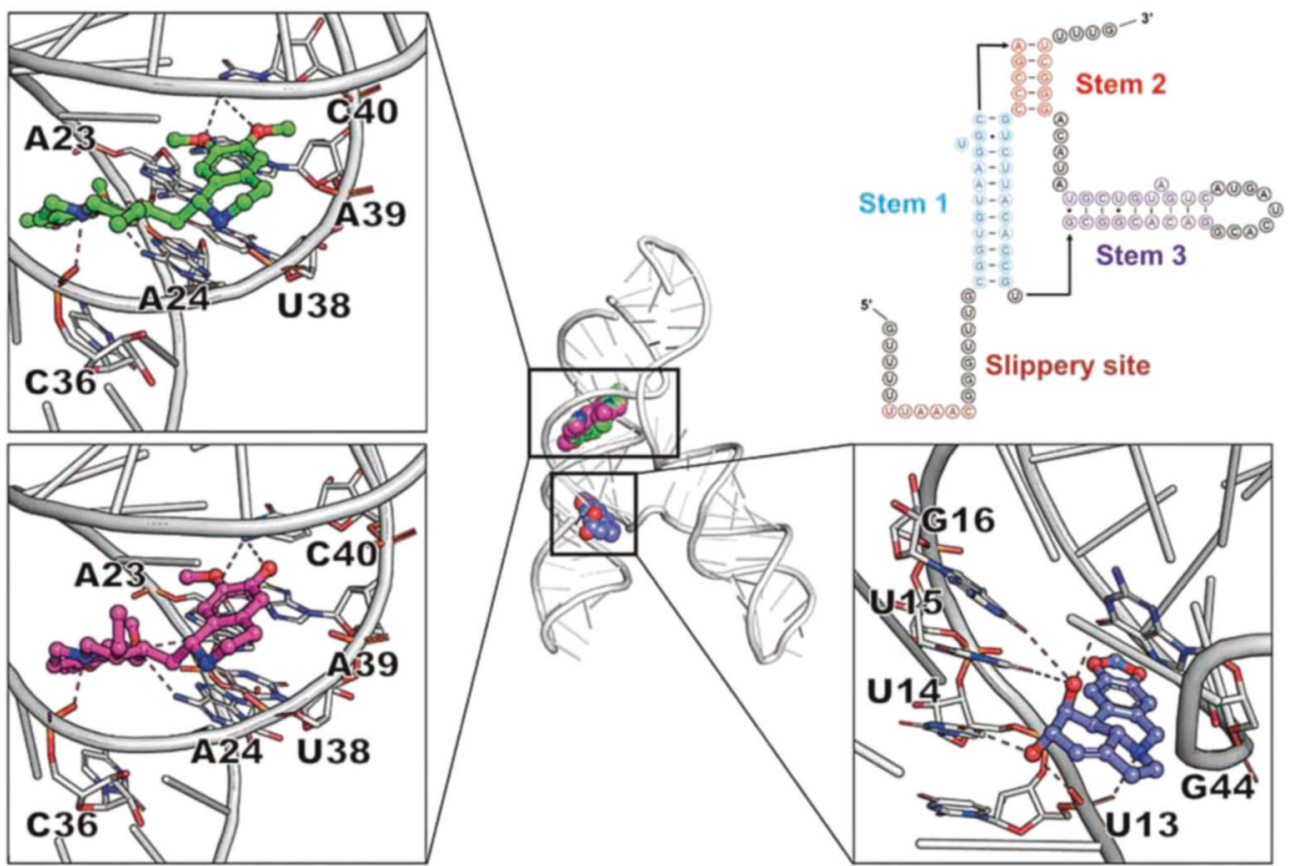

Fig. 3 Lycorine, emetine and cephaeline may attenuate SAR-CoV-2 propagation by binding with frame shift stimulation element (FSE). Predicted binding modes of these ligands with FSE. The Cartoon model represents FSE (gray). Lycorine (blue), emetine (green) and cephaeline (magentas) bound at the binding sites are depicted as stick-ball models. The interaction ribonucleotides are depicted as sticks in the zoom-up models. Red dash lines are hydrogen bonds or salt bridges formed between the ligand and FSE. The secondary structure is shown at upper right.

Lycorine, emetine, and cephaeline may attenuate SAR-CoV-2 propagation

The -1 programmed ribosomal frameshifting ( $-1 \mathrm{PRF})$, stimulated by a structured RNA motif of the SARS-CoV-2 genome, is a key translational recoding mechanism of SARS-CoV-2. The structured RNA motif, termed frameshift stimulation element (FSE), includes a 5 'heptanucleotide 'slippery site' UUUAAAC and a three-stem pseudoknot [42]. Previous studies showed that the RNA pseudoknot could be used as one potential target for developing small-molecular anti-virus drugs via attenuating viral propagation $[43,44]$. According to our computational prediction, as shown in Fig. 3, our alkaloids mentioned above also show very potential strong interaction with FSE. Generally, all these three compounds can act on the groove of stem 1, but the binding sites are slightly different. Lycorine binds against the position near the slippery site, while emetine and cephaeline are located at the site being next to stem 2. A salt-bridge interaction between the amine group of lycorine and the phosphodiester linkage of U13 can be observed, which may contribute to a dominant interaction between the compound and RNA. The binding could be further strengthened by a complicated hydrogen bond network between the two hydroxyl groups of lycorine and ribonucleotides. Emetine and cephaeline were observed to be stuck in a bigger groove through salt-bridge interaction with two phosphodiester linkages of bases of C36 and U38. Besides that, multiple hydrogen bonds, which can contribute to stabilization of emetine and cephaeline, were identified. Altogether, these results indicate that lycorine, emetine and cephaeline may attenuate SAR-CoV-2 propagation by binding with FSE.

Lycorine, emetine, and cephaeline may inhibit SARS-CoV-2 RdRp activity

To determine whether these three compounds can bind with RdRp of SARS-CoV-2 to contribute to their anti-viral activity as we predicted, we used SPR (surface plasmon resonance) to examine the binding ability of them with $\operatorname{RdRp}(n s p-12)$ catalytic subunit. As a result, lycorine was not found to bind with $\mathrm{RdRp}$ in a concentration-dependent way being without RNA but presented an apparent strong interaction with it while RNA was presented (Figs. $4 \mathrm{a}$ and $5 \mathrm{a}$ ). As a result, emetine and cephaeline were proved to bind with nsp-12 with a dissociation constant $\left(K_{\mathrm{D}}\right)$ of $25.7 \mu \mathrm{M}$ and $19.6 \mu \mathrm{M}$, respectively (Fig. $4 \mathrm{~b}, \mathrm{c}$ ). Interestingly, a ten-fold increase in binding affinities of these two compounds was observed in the system of RdRp with the presence of RNA (Fig. 5b, c). These results are agreed well with the computational prediction, as shown in Figs. $4 d$ and $5 d$, where lycorine is too small to sojourn such an extremely large cavity of RdRp. However, after binding with RNA, the cavity of RdRp became compact and in favor of the binding of these molecules, especially for the smaller lycorine. The binding affinities come up to $8.3 \mu \mathrm{M}$ (lycorine), $8.0 \mu \mathrm{M}$ (emetine), and $8.9 \mu \mathrm{M}$ (cephaeline) (Fig. 5a-c). As shown in Fig. 4d, emetine and cephaeline are bound to the conserved catalytic center of RdRp where contains two negatively charged residues (D760 and D761) through salt-bridge interaction. The catalytic site comprising of S759, D760, and D761 was ever reported critical to the function of RdRp and can form strong contacts with remdesivir, an FDAapproved anti-COVID-19 drug. The strong interactions of these residues with our molecules may infer their action mechanism of inhibiting the catalytic activity of the enzyme of RdRp. Also, the ethyl group at the benzo[a]quinolizine ring forms a hydrophobic interaction with the residue of L758. The quinolizine ring was observed to occupy the RNA primer strand binding position. Taking into account binding affinities determined by SPR experiments and the binding modes predicted by the computational technologies, these small molecules may interact with RdRp no matter with RNA or not. While the RdRp is in an apo state, the small molecules may occupy its RNA binding site quickly via taking advantage of association kinetics rates compared with large RNA. Despite their weak binding affinity, they can moderately interfere with the recognition between RNA and RdRp. After binding with RNA, the small molecules can also enter into the complex, and further being stabilized by nucleotide bases of RNA. As illustrated 


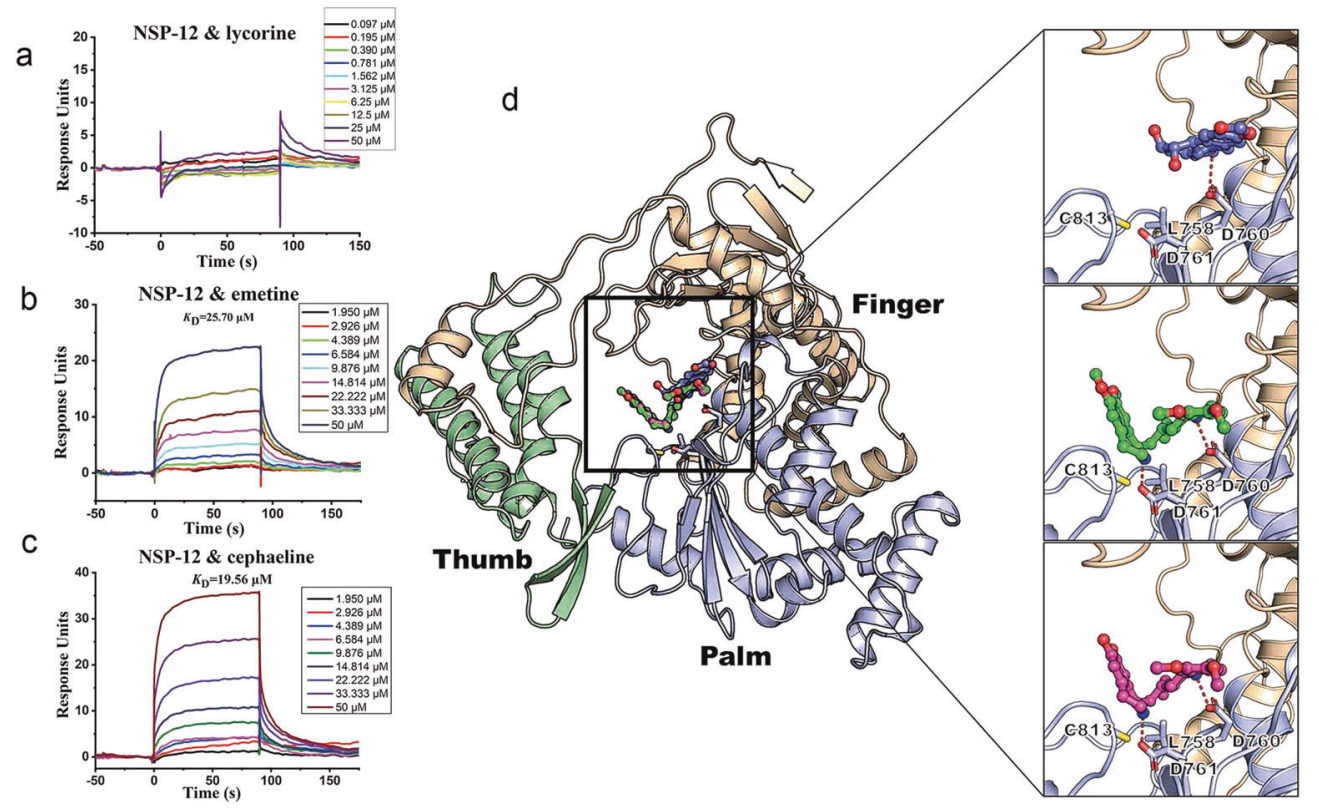

Fig. 4 Emetine and cephaeline may inhibit SARS-CoV-2 transcription by competitively blocking the binding of the RNA template-product duplex to RdRp. a Representative dose-dependent response curves for lycorine, $\mathbf{b}$ emetine, $\mathbf{c}$ cephaeline binding with nsp-12 in solution obtained from SPR assay. The detailed kinetic data obtained from SPR is collected in Table S1. d The Cartoon model represents the catalytic part of nsp-12 protein including three domains of the finger (wheat), palm (lightblue) and thumb (palegreen). Lycorine (blue), emetine (green) and cephaeline (magentas) bound at the active sites are represented as stick-ball models. The interaction residues are depicted as sticks in the zoom-up models. Red dash lines are hydrogen bonds or salt bridges formed between the ligand and proteins.
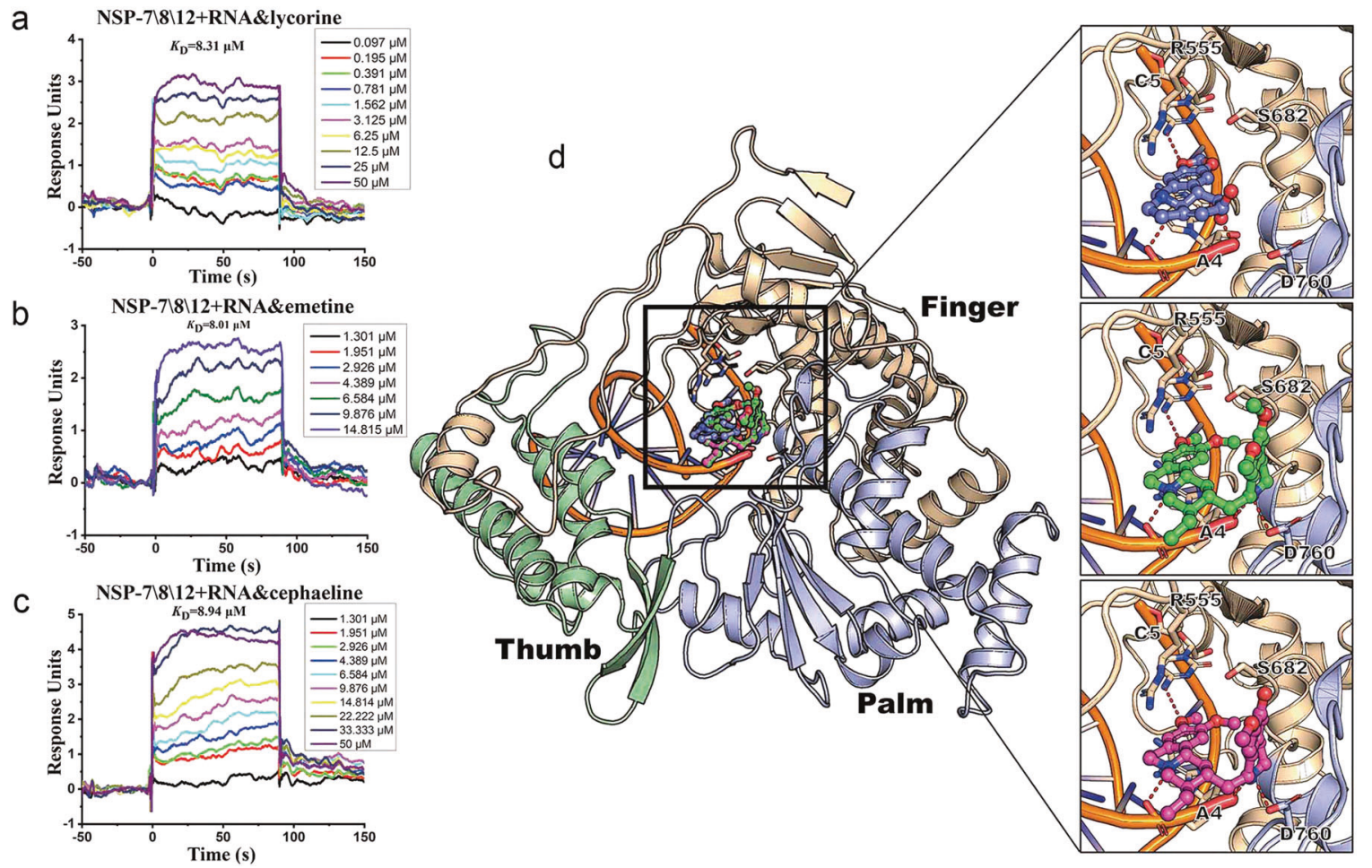

Fig. 5 Lycorine, emetine and cephaeline may inhibit SARS-CoV-2 transcription by interfering with the function of RNA on its growth site of RdRp. a Representative dose-dependent response curves for lycorine, $\mathbf{b}$ emetine, c cephaeline binding with nsp-7\8\12 and RNA complex in solution obtained from SPR assay. d Predicted binding modes of these ligands with the complex of RdRp and RNA. The Cartoon model represents the catalytic part of nsp-12 protein including three domains of the finger (wheat), palm (lightblue) and thumb (palegreen) domains. Lycorine (blue), emetine (green) and cephaeline (magentas) bound at the active sites are depicted as stick-ball models. RNA is shown as yellow cartoon model. The interaction residues are depicted as sticks in the zoom-up models. Red dash lines are hydrogen bonds or salt bridges formed between the ligand and proteins. 
in Figs. $4 d$ and $5 d$, within the existence of RNA, the binding modes of these molecules presented distinct differences. Our molecular docking studies showed that these compounds could bind to the RNA growth site (Fig. 5d), through mimicking base-stacking interactions with RNA production A4. As shown in Fig. 5d, an electrostatic contact between the phosphodiester linkage of A4 of the RNA and the amine group of these compounds can be observed. Besides that, multiple hydrogen bonds and hydrophobic contacts, which stabilize the bindings of these molecules, are observed between the ligands and RNA as well as RdRp. Especially, a shared ionic bond is observed between emetine(cephaeline) and the critical catalytic residue D760. Altogether, these results indicated that emetine and cephaeline potently inhibit SARSCoV-2 replication and transcription by blocking the binding of the RNA template-product duplex or occupying the RNA growth site, while lycorine inhibits RNA synthesis by occupying the RNA growth site.

Lycorine, emetine, and cephaeline may play a role in preventing the maturation of the virus from destroying viral core assembly We also experimentally evaluated whether the three compounds could bind to $\mathrm{N}$ protein by SPR assays. The obtained binding affinities of emetine, cephaeline, and lycorine binding with $\mathrm{N}$ protein were determined as $18.6 \mu \mathrm{M}, 53.8 \mu \mathrm{M}$, and $58.2 \mu \mathrm{M}$, respectively (Fig. $6 \mathrm{a}-\mathrm{C}$ ). As shown in Fig. $6 \mathrm{~d}-\mathrm{f}$, the binding site of $\mathrm{N}$ protein is relatively large and flat, and therefore, is very challenging to design strongly bound molecules. Then this can somehow explain why these experimentally obtained binding affinities are relatively weak. As shown in Fig. 6, the three compounds were all found to be able to form a $\pi-\pi$ interaction with Y109 of $\mathrm{N}$ protein. Additional hydrogen bonds between emetine as well as cephaeline and the residues of T91 and Y109 of the protein were observed. While lycorine forms a hydrogen bond with R149. Therefore, the results suggest that the three compounds may also interfere with viral core assembly and maturation by blocking the recognition between the viral genome $\mathrm{N}$ protein.

Antiviral activities and cytotoxicity measurement for lycorine, emetine, and cephaeline

We further evaluated the antiviral efficacy of the three compounds against SARS-CoV-2 in Vero E6 cells. The antiviral efficacies were evaluated by quantifying the viral copy numbers in the cell supernatant via qRT-PCR. The results showed the dose-dependent inhibition by the three compounds for SARS-CoV-2 replication, and the $\mathrm{EC}_{50}$ were respectively $0.439 \pm 0.122 \mu \mathrm{M}, 0.00771 \pm$ $0.000117 \mu \mathrm{M}$, and $0.0123 \pm 0.000503 \mu \mathrm{M}$ (Fig. 7a). The cytotoxicity of the three compounds in Vero E6 was determined by the CCK8 assay, and the $\mathrm{CC}_{50}$ were respectively $>1000 \mu \mathrm{M}, 2.170 \pm 0.258 \mu \mathrm{M}$, $49.048 \pm 46.327 \mu \mathrm{M}$ (Fig. 7b). We also determined the cytotoxicity of the three compounds in Huh-7 cells and HEK293T cells, and the $\mathrm{CC}_{50}$ in Huh-7 cells were respectively $0.834 \pm 0.0630 \mu \mathrm{M}, 0.0334 \pm$ $0.000617 \mu \mathrm{M}$, and $3.035 \pm 1.699 \mu \mathrm{M}$; the $\mathrm{CC}_{50}$ in HEK293T cells were respectively $1.044 \pm 0.0734 \mu \mathrm{M}, 0.0378 \pm 0.000562 \mu \mathrm{M}$, and $1.995 \pm 0.468 \mu \mathrm{M}$ (Supplementary Fig. S6). These findings showed suitable antiviral activities of lycorine, emetine and cephaeline in Vero E6 cells, but certain toxic effects in both Huh-7 cells and HEK293T cells. According to our findings and previous literatures, the toxic effects of these drugs are largely caused by their interactions with the human ribosomes. Hence, selectively decreasing the binding affinities of these compounds with ribosomes by modifying the compound structures will be an extended research of this study.

\section{DISCUSSION}

Lycorine, a natural alkaloid extracted from the amaryllidaceae plant Lycoris radiate, also a traditional Chinese medicine herb, is previously reported to have multiple biological properties, such as anti-parasite, anti-bacterial, anti-tumor, anti-inflammatory, antiplasmodia, and anti-virus [45]. Emetine, the principal alkaloid of ipecac root, is an antiprotozoal and emetine drug, which has also been demonstrated to have several biological functions, including contraceptive activities, anti-cancer, and anti-virus [46]. During the preparation of this manuscript, the anti-SARS-CoV-2 activities of lycorine and emetine were reported, i.e., lycorine has an anti-SARSCoV- 2 of $\mathrm{EC}_{50}=0.31 \mu \mathrm{M}$, and emetine has an of $\mathrm{EC}_{50}=0.46 \mu \mathrm{M}$ [47-49]. The reported anti-virus activity of lycorine is like ours $\left(E C_{50}=0.439 \pm 0.122 \mu \mathrm{M}\right)$, while the emetine showed a much better inhibitory activity in our test $\left(E_{50}=0.00771 \pm 0.000117\right.$ $\mu \mathrm{M})$. However, their molecular mechanisms of action are still not clear.

The broad-spectrum antiviral activities of emetine and lycorine have been reported $[38,50-56]$. It was reported that lycorine and emetine may be able to block the synthesis of the viral proteins of Zika virus, BPXV (buffalopoxvirus) or NDV (Newcastle disease virus) by inhibiting the function of the ribosomes of host cells $[39,55]$. Moreover, the inhibition mechanisms of lycorine and emetine for eukaryotic ribosomes were further demonstrated respectively by complex structures released by X-ray diffraction and Cryo-EM analyses. According to their binding sites on the ribosome, it seems that lycorine inhibits protein synthesis by interfering with the peptide-bond formation, while emetine inhibits protein synthesis by blocking the E-site $[12,40]$, which is a site for deacylated tRNA molecules before they dissociate from the ribosome. By considering these findings, human ribosome structures complex with the three compounds were computationally modeled. Given the favorable molecular interactions formed between the ligands and ribosome as well as reports from other literature, the hindrance of the translation of viral proteins can be confirmed. However, this may lead to certain cytotoxicity.

Previous studies showed that lycorine and emetine could inhibit RNA polymerase of Zika virus [38, 39]. This study reported their potential inhibition ability against the RNA polymerase of SARSCoV-2 and proposed its potential double-faced molecular mechanisms of suppressing replication and transcription, i.e., emetine and cephaeline may block the RNA template-product duplex or occupying the RNA growth site. On the other hand, our computational simulations indicate that these positively charged compounds could strongly bind to the negatively charged -1 RPF of SARS-CoV2 , contributing to impairing the propagation of the virus. Finally, we found that lycorine, emetine, and cephaeline may bind with $\mathrm{N}$ proteins by SPR assay and molecular docking study, presenting a potential in disrupting the virus-assembly process. The cell-based viral infection assay was also performed to test the potent antivirals activities of lycorine, emetine, and cephaeline in Vero E6 cell. The effective concentration in the cell-based viral infection assay is smaller than the molecular level assay, which suggested the multiple-target activities of the three compounds.

There are other potential antiviral activities for lycorine, emetine, and cephaeline. Chloroquine was reported to inhibit the endocytic pathway of SARS-CoV-2 by altering the $\mathrm{pH}$ of endosomes due to its alkalinity [34, 35, 57-59]. Same as chloroquine, we speculate that the three alkaloids can also affect the virus with similar mechanisms, such as blocking the entry into the host cell by altering the $\mathrm{pH}$ of the endosomes.

Previous animal toxicological experiments exhibited low toxicity and mild side effects of lycorine [60]. In addition, it was reported that SARS-CoV-2 virus has an infect on the brain tissues [61]. Lycorine is able to cross the blood-brain barrier which suggests that it has the potential of treating brain infection [62]. Although emetine has been known as a therapeutic drug since the 17th century, the sideways of myopathy and cardiomyopathy should be considered for further evaluation [63-65]. Altogether, lycorine, emetine, and cephaeline show certain anti-SARS-CoV-2 potential. More importantly, our multi-targeted anti-virus drug design 
a

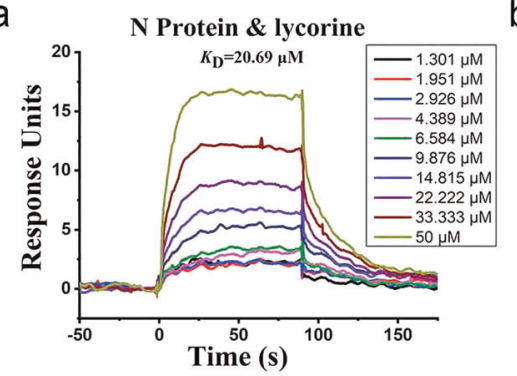

d

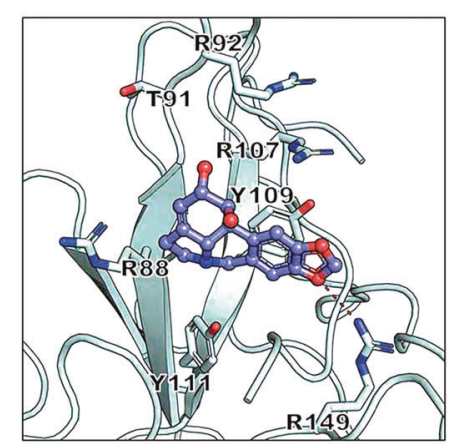

b

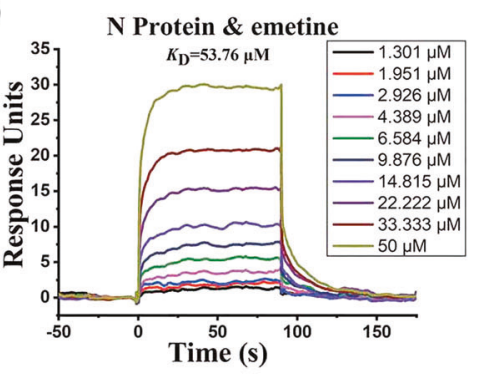

e

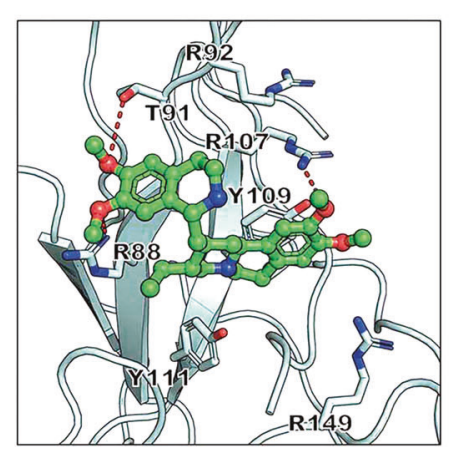

C

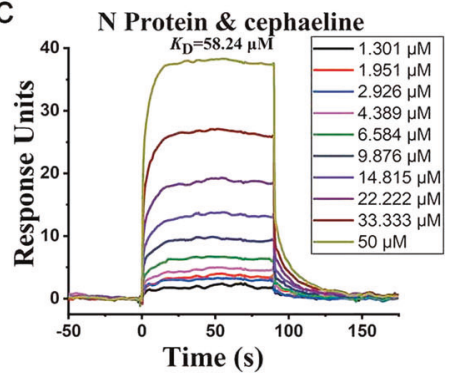

$f$

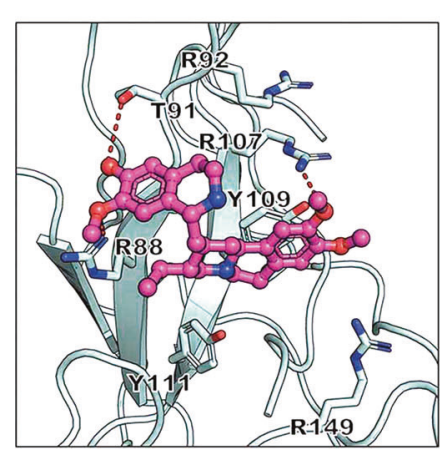

Fig. 6 Lycorine, emetine and cephaeline may inhibit the assembly of SARS-CoV-2 virions. a Representative response curve for lycorine, b emetine, $\mathbf{c}$ cephaeline binding with $\mathrm{N}$ protein in solution, resulting from SPR assay. The detailed kinetic data obtained from SPR are collected in Table S2. $\mathbf{d}-\mathbf{f}$ Predicted binding modes of these ligands with $\mathrm{N}$ protein. The cartoon model represents $\mathrm{N}$ protein (palecyan). Lycorine (blue), emetine (green) and cephaeline (magentas) bound at the active sites are depicted as stick-ball models. The interaction residues are depicted as sticks. Red dash lines are hydrogen bonds or salt bridges formed between the ligand and proteins.

a

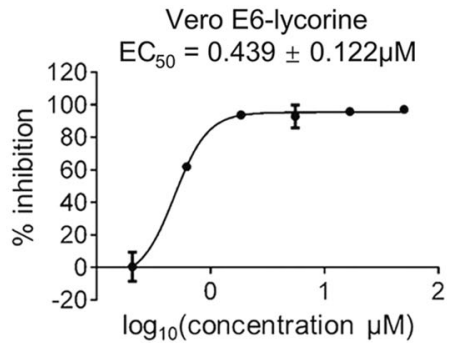

b

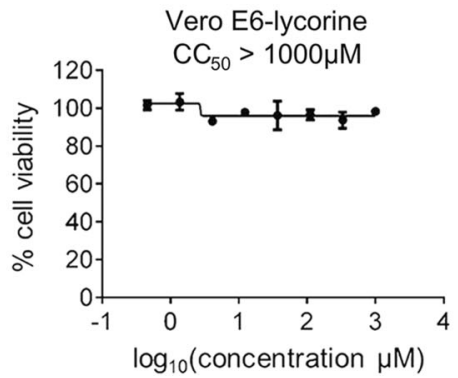

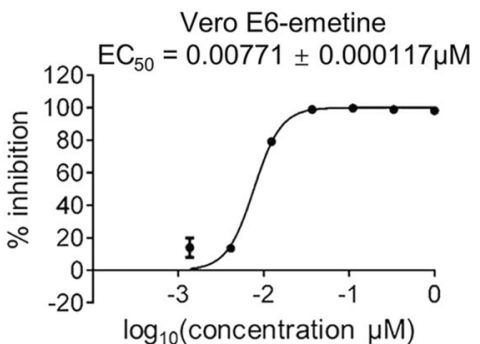
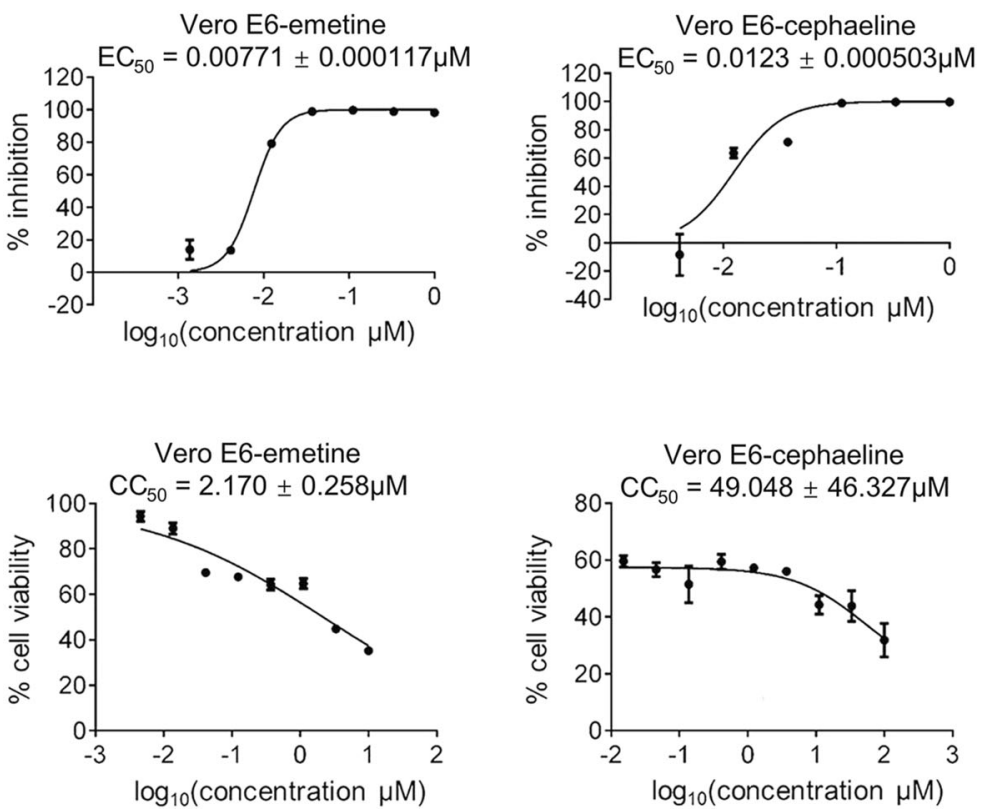

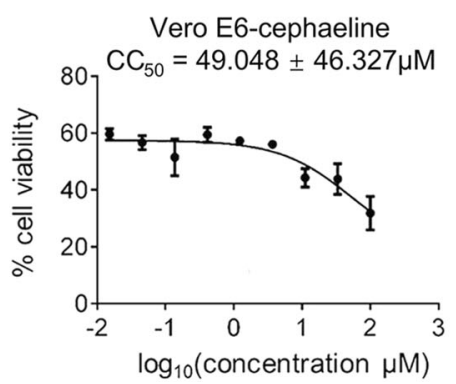

Fig. 7 In vitro inhibitory activity profiles of compounds against SARS-CoV-2. Vero E6 cells infected with SARS-CoV-2 at an MOI of 0.01 were treated with different concentrations of compounds. a Quantitative RT-PCR assays were performed to measure the viral copy number in cellular supernatant. The $y$ axis indicates percentage inhibition of virus relative to sample treated with DMSO (vehicle); $\mathbf{b}$ Cell viability assay in Vero E6 cells. The $y$ axis represents the percentage of cell viability relative to the sample treated with DMSO (vehicle). Data are shown as mean $\pm S D, n=3$.

strategy may provide a new avenue for rational drug design for SARS-CoV-2, even other viruses.

\section{CONCLUSION}

In this study, three highly potent anti-SARS-CoV-2 inhibitors, lycorine, emetine, and cephaeline, were identified by a multi- target driven anti-virus drug design strategy. It was found that these compounds may show the anti-virus activities by simultaneously targeting the host ribosome, and viral RNA, RdRp as well as $\mathrm{N}$ protein to interfere with the translating, propagating, replicating, and assembling process of the virus. The findings presented in this study show the applicability and feasibility of this novel multi-target driven anti-virus drug design strategy. 
Meanwhile, it indicated that more potent and safer drugs could be designed by improving their bindings with the targets of the virus, but reducing their interactions with the host ribosome.

\section{ACKNOWLEDGEMENTS}

This work was supported by the Science and Technology Commission of Shanghai Municipality grants (Grant IDs: 20431900102, 20431900100, and 20430780300); Shanghai Science and Technology Development Funds (Grant ID: 20QA1406400); the Youth Innovation Promotion Association CAS (grants 2018367 to L.-K.Z). the National Science \& Technology Major Project "Key New Drug Creation and Manufacturing Program", China (Grant ID: 2018ZX09711002); National Natural Science Foundation of China (No. 82003654); as well as the start-up package from ShanghaiTech University.

\section{AUTHOR CONTRIBUTIONS}

PXR, LW, BQL, HLL, HLJ, and FB performed computational simulations and analysis. $\mathrm{HG}, \mathrm{XLZ}$, and LLZ performed the SPR assays and did the analysis. WCY, YCX, and EHX prepared the protein and RNA samples, performed the experimental validations with the other members. WJS and LKZ performed antiviral activities measurement in cells. All the authors were involved in writing the manuscripts.

\section{ADDITIONAL INFORMATION}

Supplementary information The online version contains supplementary material available at https://doi.org/10.1038/s41401-021-00668-7.

Competing interests: The authors declare no competing interests.

\section{REFERENCES}

1. Zhu N, Zhang D, Wang W, Li X, Yang B, Song J, et al. A novel coronavirus from patients with pneumonia in China, 2019. N Engl J Med. 2020;382:727-33.

2. Holshue ML, DeBolt C, Lindquist S, Lofy $\mathrm{KH}$, Wiesman J, Bruce $\mathrm{H}$, et al. First case of 2019 novel coronavirus in the United States. N Engl J Med. 2020;382:929-36.

3. Lillie PJ, Samson A, Li A, Adams K, Capstick R, Barlow GD, et al. Novel coronavirus disease (Covid-19): The first two patients in the UK with person to person transmission. J Infect. 2020;80:578-606.

4. Dong E, Du H, Gardner L. An interactive web-based dashboard to track COVID-19 in real time. Lancet Infect Dis. 2020;20:533-4.

5. Zhou $P$, Yang XL, Wang XG, Hu B, Zhang L, Zhang W, et al. A pneumonia outbreak associated with a new coronavirus of probable bat origin. Nature. 2020;579:270-3.

6. Brian DA, Baric RS. Coronavirus genome structure and replication. In: Enjuanes L., editor. Coronavirus replication and reverse genetics. Berlin, Heidelberg: Springer Berlin Heidelberg; 2005. p. 1-30.

7. Su S, Wong G, Shi W, Liu J, Lai ACK, Zhou J, et al. Epidemiology, genetic recombination, and pathogenesis of coronaviruses. Trends Microbiol. 2016;24:490-502.

8. Kim D, Lee JY, Yang JS, Kim JW, Kim VN, Chang H. The architecture of SARS-CoV-2 transcriptome. Cell. 2020;181:914-21.e10.

9. Fehr AR, Perlman S. Coronaviruses: an overview of their replication and pathogenesis. In: Maier HJ, Bickerton E, Britton P, editors. Coronaviruses: methods and protocols. New York, NY: Springer New York; 2015. p. 1-23.

10. Sonenberg N, Hinnebusch AG. Regulation of translation initiation in eukaryotes: mechanisms and biological targets. Cell. 2009;136:731-45.

11. Liljas A. Ribosomes. In: Maloy S, Hughes K, editors. Brenner's encyclopedia of genetics (Second Edition). San Diego: Academic Press; 2013. p. 248-253.

12. Garreau de Loubresse N, Prokhorova I, Holtkamp W, Rodnina MV, Yusupova G, Yusupov M. Structural basis for the inhibition of the eukaryotic ribosome. Nature. 2014:513:517-22.

13. $\mathrm{Wu} \mathrm{Cl}$, Wen $\mathrm{H}$. Heightened protein-translation activities in mammalian cells and the disease/treatment implications. Natl Sci Rev. 2020;7:1851-5.

14. Neupane K, Munshi S, Zhao M, Ritchie DB, lleperuma SM, Woodside MT. Antiframeshifting ligand active against SARS Coronavirus-2 is resistant to natural mutations of the frameshift-stimulatory pseudoknot. J Mol Biol. 2020;432:5843-7.

15. Haniff HS, Tong Y, Liu X, Chen JL, Suresh BM, Andrews RJ, et al. Targeting the SARS-CoV-2 RNA genome with small molecule binders and ribonuclease targeting chimera (RIBOTAC) degraders. ACS Central Sci. 2020;6:1713-21.

16. Plant EP, Sims AC, Baric RS, Dinman JD, Taylor DR. Altering SARS coronavirus frameshift efficiency affects genomic and subgenomic RNA production. Viruses. 2013;5:279-94.
17. Machitani M, Yasukawa M, Nakashima J, Furuichi Y, Masutomi K. RNA-dependent RNA polymerase, RdRP, a promising therapeutic target for cancer and potentially COVID-19. Cancer Sci. 2020;111:3976-84.

18. Allen CNS, Arjona SP, Santerre M, Sawaya BE. Potential use of RNA-dependent RNA polymerase (RdRp) inhibitors against SARS-CoV2 infection. All Life. 2020;13:608-14.

19. Gao $Y$, Yan L, Huang Y, Liu F, Zhao Y, Cao L, et al. Structure of the RNA-dependent RNA polymerase from COVID-19 virus. Science. 2020;368:779.

20. Yin W, Mao C, Luan X, Shen DD, Shen Q, Su H, et al. Structural basis for inhibition of the RNA-dependent RNA polymerase from SARS-CoV-2 by remdesivir. Science. 2020;368:1499-504.

21. Wang $\mathrm{Q}$, Wu J, Wang $\mathrm{H}, \mathrm{Gao} \mathrm{Y}$, Liu $\mathrm{Q}, \mathrm{Mu}$ A, et al. Structural basis for RNA replication by the SARS-CoV-2 polymerase. Cell. 2020;182:417-28.e13.

22. Cascarina SM, Ross ED. A proposed role for the SARS-CoV-2 nucleocapsid protein in the formation and regulation of biomolecular condensates. FASEB J. 2020;34:9832-42.

23. McBride R, van Zyl M, Fielding B. The coronavirus nucleocapsid is a multifunctional protein. Viruses. 2014;6:2991-3018.

24. Cong $Y$, Ulasli $M$, Schepers $H$, Mauthe $M$, V'kovski $P$, Kriegenburg $F$, et al. Nucleocapsid protein recruitment to replication-transcription complexes plays a crucial role in coronaviral life cycle. J Virol. 2020;94:e01925-19.

25. Lin SY, Liu CL, Chang YM, Zhao J, Perlman S, Hou MH. Structural basis for the identification of the $\mathrm{N}$-terminal domain of coronavirus nucleocapsid protein as an antiviral target. J Med Chem. 2014;57:2247-57.

26. Zheng W, Li Y, Zhang C, Pearce R, Mortuza SM, Zhang Y. Deep-learning contactmap guided protein structure prediction in CASP13. Proteins. 2019;87:1149-64.

27. Yang J, Anishchenko I, Park H, Peng Z, Ovchinnikov S, Baker D. Improved protein structure prediction using predicted interresidue orientations. Proc Natl Acad Sci USA. 2020;117:1496-503.

28. UniProt C. UniProt: a worldwide hub of protein knowledge. Nucleic Acids Res. 2019;47:D506-D515.

29. Madeira F, Park YM, Lee J, Buso N, Gur T, Madhusoodanan N, et al. The EMBL-EBI search and sequence analysis tools APIs in 2019. Nucleic Acids Res. 2019;47: W636-W641.

30. Robert X, Gouet P. Deciphering key features in protein structures with the new ENDscript server. Nucleic Acids Res. 2014;42:W320-W324.

31. Halgren TA, Murphy RB, Friesner RA, Beard HS, Frye LL, Pollard WT, et al. Glide: a new approach for rapid, accurate docking and scoring. 2. Enrichment factors in database screening. J Med Chem. 2004;47:1750-9.

32. Wang M, Cao R, Zhang L, Yang X, Liu J, Xu M, et al. Remdesivir and chloroquine effectively inhibit the recently emerged novel coronavirus (2019-nCoV) in vitro. Cell Res. 2020;30:269-71.

33. Jin Z, Du X, Xu Y, Deng $Y$, Liu $M$, Zhao $Y$, et al. Structure of $M($ pro) from SARS-CoV2 and discovery of its inhibitors. Nature. 2020;582:289-93.

34. Quiros Roldan E, Biasiotto G, Magro P, Zanella I. The possible mechanisms of action of 4-aminoquinolines (chloroquine/hydroxychloroquine) against Sars-Cov2 infection (COVID-19): a role for iron homeostasis? Pharm Res. 2020;158:104904.

35. Satarker S, Ahuja T, Banerjee M, E VB, Dogra S, Agarwal T, et al. Hydroxychloroquine in COVID-19: potential mechanism of action against SARS-CoV-2. Curr Pharm Rep. 2020;6:203-11.

36. Kirchdoerfer RN, Ward AB. Structure of the SARS-CoV nsp12 polymerase bound to nsp7 and nsp8 co-factors. Nat Commun. 2019;10:2342.

37. Gupta RS, Krepinsky JJ, Siminovitch L. Structural determinants responsible for the biological activity of (-)-emetine, (-)-cryptopleurine, and (-)-tylocrebrine: structureactivity relationship among related compounds. Mol Pharmacol. 1980;18:136-43.

38. Yang S, Xu M, Lee EM, Gorshkov K, Shiryaev SA, He S, et al. Emetine inhibits Zika and Ebola virus infections through two molecular mechanisms: inhibiting viral replication and decreasing viral entry. Cell Discov. 2018;4:31.

39. Chen H, Lao Z, Xu J, Li Z, Long H, Li D, et al. Antiviral activity of lycorine against Zika virus in vivo and in vitro. Virology. 2020;546:88-97.

40. Wong W, Bai XC, Brown A, Fernandez IS, Hanssen E, Condron M, et al. Cryo-EM structure of the plasmodium falciparum $80 \mathrm{~S}$ ribosome bound to the antiprotozoan drug emetine. Elife. 2014;3:e03080.

41. Anger AM, Armache JP, Berninghausen $O$, Habeck $M$, Subklewe $M$, Wilson DN, et al. Structures of the human and Drosophila 80S ribosome. Nature. 2013;497:80-5.

42. Zhang K, Zheludev IN, Hagey RJ, Wu MT, Haslecker R, Hou YJ, et al. Cryo-electron microscopy and exploratory antisense targeting of the 28-kDa frameshift stimulation element from the SARS-CoV-2 RNA genome. bioRxiv. 2020 Jul 20:2020.07.18.209270. https://doi.org/10.1101/2020.07.18.209270.

43. Park SJ, Kim YG, Park HJ. Identification of RNA pseudoknot-binding ligand that inhibits the -1 ribosomal frameshifting of SARS-coronavirus by structure-based virtual screening. J Am Chem Soc. 2011;133:10094-100.

44. Sun Y, Abriola L, Surovtseva YV, Lindenbach BD, Guo JU. Restriction of SARS-CoV2 replication by targeting programmed -1 ribosomal frameshifting in vitro. bioRxiv. 2020;2020.10.21.349225. https://doi.org/10.1101/2020.10.21.349225. 
45. Cao Z, Yang $P$, Zhou Q. Multiple biological functions and pharmacological effects of lycorine. Sci China Chem. 2013;56:1382-91.

46. Emmanuel S, Akinboye OB. Biological activities of emetine. Open Nat Products J. 2011;4:8-15.

47. Choy KT, Wong AY, Kaewpreedee P, Sia SF, Chen D, Hui KPY, et al. Remdesivir, lopinavir, emetine, and homoharringtonine inhibit SARS-CoV-2 replication in vitro. Antivir Res. 2020;178:104786.

48. lanevski A, Yao R, Fenstad MH, Biza S, Zusinaite E, Reisberg T, et al. Potential antiviral options against SARS-CoV-2 infection. Viruses. 2020;12:642.

49. Zhang YN, Zhang QY, Li XD, Xiong J, Xiao SQ, Wang Z, et al. Gemcitabine, lycorine and oxysophoridine inhibit novel coronavirus (SARS-CoV-2) in cell culture. Emerg Microbes Infect. 2020;9:1170-3.

50. Guo Y, Wang Y, Cao L, Wang P, Qing J, Zheng Q, et al. A conserved inhibitory mechanism of a lycorine derivative against enterovirus and hepatitis $C$ virus. Antimicrob Agents Chemother. 2016;60:913-24.

51. Khalifa SAM, Yosri N, El-Mallah MF, Ghonaim R, Guo Z, Musharraf SG, et al. Screening for natural and derived bio-active compounds in preclinical and clinical studies: one of the frontlines of fighting the coronaviruses pandemic. Phytomedicine. 2021;85:153311. https://doi.org/10.1016/j.phymed.2020.153311.

52. Liu J, Yang Y, Xu Y, Ma C, Qin C, Zhang L, et al. Lycorine reduces mortality of human enterovirus 71-infected mice by inhibiting virus replication. Virol J. 2011;8:483.

53. Zou G, Puig-Basagoiti F, Zhang B, Qing M, Chen L, Pankiewicz KW, et al. A single-amino acid substitution in West Nile virus $2 \mathrm{~K}$ peptide between NS4A and NS4B confers resistance to lycorine, a flavivirus inhibitor. Virology. 2009;384:242-52.

54. Deng L, Dai P, Ciro A, Smee DF, Djaballah H, Shuman S. Identification of novel antipoxviral agents: mitoxantrone inhibits vaccinia virus replication by blocking virion assembly. J Virol. 2007;81:13392-402.
55. Khandelwal N, Chander Y, Rawat KD, Riyesh T, Nishanth C, Sharma S, et al Emetine inhibits replication of RNA and DNA viruses without generating drugresistant virus variants. Antivir Res. 2017;144:196-204.

56. Andersen PI, Krpina K, lanevski A, Shtaida N, Jo E, Yang J, et al. Novel antiviral activities of obatoclax, emetine, niclosamide, brequinar, and homoharringtonine. Viruses. 2019;11:964.

57. Barrow E, Nicola AV, Liu J. Multiscale perspectives of virus entry via endocytosis. Virol J. 2013;10:177.

58. Sun $Y$, Tien P. From endocytosis to membrane fusion: emerging roles of dynamin in virus entry. Crit Rev Microbiol. 2013;39:166-79.

59. Oscanoa TJ, Romero-Ortuno R, Carvajal A, Savarino A. A pharmacological perspective of chloroquine in SARS-CoV-2 infection: an old drug for the fight against a new coronavirus? Int J Antimicrob Agents. 2020;56:106078.

60. Vrijsen R, Vanden Berghe DA, Vlietinck AJ, Boeyé A. Lycorine: a eukaryotic ter mination inhibitor? J Biol Chem. 1986;261:505-7.

61. Bullen CK, Hogberg HT, Bahadirli-Talbott A, Bishai WR, Hartung T, Keuthan C, et al. Infectability of human BrainSphere neurons suggests neurotropism of SARS-CoV-2. Altex. 2020;37:665-71.

62. Lamoral-Theys D, Andolfi A, Van Goietsenoven G, Cimmino A, Le Calvé B, Wauthoz $\mathrm{N}$, et al. Lycorine, the main phenanthridine amaryllidaceae alkaloid, exhibits significant antitumor activity in cancer cells that display resistance to proapoptotic stimuli: an investigation of structure-activity relationship and mechanistic insight. J Med Chem. 2009;52:6244-56.

63. Hopf NJ, Goebel HH. Experimental emetine myopathy: enzyme histochemical electron microscopic, and immunomorphological studies. Acta Neuropathol. 1993;85:414-8.

64. Pan SJ, Combs AB. Effects of pharmacological interventions on emetine cardiotoxicity in isolated perfused rat hearts. Toxicology. 1995;97:93-104

65. Pan SJ, Combs AB. Emetine inhibits glycolysis in isolated, perfused rat hearts. Cardiovasc Toxicol. 2003;3:311-8. 